\title{
Diverse complexities, complex diversities: Resisting 'normal science' in pedagogical and research methodologies. A perspective from Aotearoa (New Zealand)
}

Jenny Ritchie

Abstract: This paper offers an overview of complexities of the contexts for education in Aotearoa, which include the need to recognise and include Māori (Indigenous) perspectives, but also to extend this inclusion to the context of increasing ethnic diversity. These complexities include the situation of worsening disparities between rich and poor which disproportionately position Māori and those from Pacific Island backgrounds in situations of poverty. It then offers a brief critique of government policies before providing some examples of models that resist 'normal science' categorisations. These include: the Māori values underpinning the effective teachers' profile of the Kotahitanga project and of the Māori assessment model for early childhood education; the dispositions identified in a Samoan model for assessing young children's learning; and the approach developed for assessing Māori children's literacy and numeracy within schools where Māori language is the medium of instruction. These models all position learning within culturally relevant frames that are grounded in non-Western onto-epistemologies which include spiritual, cultural, and collective aspirations.

Keywords: superdiversity, New Zealand, schoolification, pedagogical resistance, spiritual wellbeing. 
Since qualitative research is contextually situated, this paper begins with an overview of the complex diversities, and diverse complexities of my research context, early childhood care and education in Aotearoa (New Zealand). This includes a critique of the deepening socioeconomic disparities that neoliberalism has engendered, including worrying health and educational outcomes for marginalised populations. It is noted that these are not being addressed by current 'normal science' informed approaches. Early childhood education policies in Aotearoa continue to focus on increasing 'participation' and 'achievement', without ensuring that the services are offering programmes that are culturally relevant. The 'schoolification' of the sector assumes that individual cognitive learning 'achievement' is the exclusively important goal, ignoring children and families' social, cultural, emotional and physical wellbeing and also collectivist and community values. 'Quality' has become a jargon buzz-word, to which services are held accountable, yet this normalised view of quality does not critique or investigate the 'qualities' that families might want their children's educational services to model and uphold. Definitions of 'quality' are no longer offered or interrogated in government education policy, and the recent imposition of 'national standards' in primary education, without consultation with teachers and communities ignores particularlities and complexities (Thrupp \& Easter, 2013) and is likely to contribute to further inequities, as middle-class families migrate their children to 'higher achieving' schools.

I then move on to discuss educator and researcher positionality and pedagogical and research methodologies, in relation to this context and to the ethical responsivity required in the light of the contextual complexities outlined. I draw upon the work of Professor Russell Bishop and other New Zealand and Pacific Islands scholars in offering some thoughts as to pathways for navigating through the diverse complexities that we encounter in our work in Aotearoa.

Thomas Kuhn critiqued 'normal science' as being 'a strenuous and devoted attempt to force nature into the conceptual boxes supplied by professional education' (Kuhn, 1970, p. 5), the nature of these boxes being as 'preformed and inflexible' as the currently accepted paradigm allows (p. 24). These paradigms inevitably 'restrict the phenomenological field accessible for scientific engagement at any given time' (p. 60). Kuhn points out that: 'The proliferation of competing articulations, the willingness to try anything, the expression of explicit discontent, the recourse to philosophy and to debate over fundamentals, all these are symptoms of a transition from normal to extraordinary research' (p. 91). In this paper, examples from Aotearoa of 
resisting normal science will offer insights into potential transitionings into 'extraordinary research' in our particular context.

\section{Contextual Overview for Researching Education in Aotearoa}

Aotearoa (New Zealand) is a country with a history of colonisation of the Indigenous Māori, by British \& Irish settlers who implemented deliberate policies of excluding racialised 'others' (Spoonley, 2015). According to the New Zealand Royal Society, "[t]he past few decades have seen large increases in the ethnic, cultural, social and linguistic diversity of the New Zealand population" (Royal Society of New Zealand, 2013, p. 1). This has resulted in the current situation of 'superdiversity' in Aotearoa (New Zealand) (Royal Society of New Zealand, 2013; Spoonley, 2015). The notion of superdiversity refers to the 'diversification of diversity' resulting from increased immigration being experienced in large metrolopolitan areas such as London, in the UK, and Auckland in New Zealand (Vertovec, 2007). It includes consideration of the interplay of factors such as ethnicity, the nature of various 'communities', their composition, trajectories, interactions and public service needs" such as educational provision (Vertovec, 2007, p. 1025).

According to our most recent national census, $39.1 \%$ of the population of our largest city, Auckland, were born outside of New Zealand (Statistics New Zealand, 2013), raising further challenges for a largely monocultural teacher workforce, who currently struggle to incorporate Māori language and culture into the curriculum, despite this being an ethical obligation under the 1840 Tiriti o Waitangi ${ }^{1}$ which is recognised in both the early childhood and 'mainstream' school curriculum documents (New Zealand Ministry of Education, 1996, 2007). Despite this having been an expectation in the early childhood sector for the past two decades, the majority of services fall short in this regard (Education Review Office, 2010, 2012, 2013). This indicates that teachers will also be challenged to move beyond their monocultural paradigm in relation to the increasing complexities of ethnic superdiversity.

Whilst New Zealand is a nation which has previously prided itself on its egalitarianism, it has in recent years experienced a comparatively severe in-

\footnotetext{
The 1840 Treaty of Waitangi was signed between the British Crown and Māori chiefs, and allowed for British settlement of New Zealand in exchange for promises to Māori of their ongoing self-determination, land rights, and equal citizenship.
} 
crease in income inequality which disproportionately affects those members of society of Māori and Pacific Islands ancestry (Marriott \& Sim, 2014; Rashbrooke, 2014a, 2014b). Social wellbeing indicators that have worsened in the past decade, in terms of increasing gaps between the dominant Pākehā population (of European ancestry) and Māori and Pacific Islands peoples include: obesity, cigarette smoking, suicide, higher degree completions, unemployment ( $\&$ the proportion of people receiving government benefits), and income level (Marriott \& Sim, 2014). Making an effort towards understanding the complexity of the interaction of these factors seems beyond the interests of the current government. Writing on the positioning of children from Pacific Islands' backgrounds in the New Zealand education system, Diane Mara considers that: 'Poverty is undoubtedly a barrier to learning' (Mara, 2014, p. 120), critiquing government policy that has exacerbated conditions of poverty experienced by Māori and Pacific Islands families as deliberate 'social containment' (p. 113). Historically, our colonial context has inculcated a deficit view of children of Māori and Pacific Islands' descent, yet 'an equally obvious explanation for educational underachievement is surely poverty and the fact that Māori and Pasifika students are over-represented among the poor' (Snook \& O'Neill, 2014, p. 37). As Manuka Henare explains, poverty not only affects Māori children's physical and emotional wellbeing, it also harms their spiritual wellbeing, their mauri or life-force, "with potentially dire long-term consequences' (2014, p. 54).

These deepening socio-economic disparities regarding health, wellbeing, economic and educational outcomes are clearly not being addressed by 'normal science' based approaches, nor the current impact of neoliberal policy approaches by government. Even apparent 'successes' of current policy need to be scrutinised more carefully than a rudimentary reading of current figures would deliver. The recent priority by the New Zealand government of increasing participation in early childhood services seems to have generated positive results (Education Counts, 2014). Figures are presented demonstrating the increased participation, and the website proclaims that:

Participation in high quality ECE has significant benefits for children and their future learning ability. Some studies have found that engagement in ECE helps to develop strong foundations for future learning success... These effects apply to all children but may be particularly important for building academic achievement in children from poorer communities and socio-economic backgrounds... (Education Counts, 2014, p. 1) 
However, there is no accompanying information that would indicate the steps that the government has put in place to ensure that the provision within the sector is actually 'high quality', nor a definition of what this might entail.

Furthermore, there is a serious ethical concern with regard to the current 'Better Social Services' policy of targetting parents receiving government benefits to compulsorarily enroll their children in a government approved early childhood service, or face punitive income reductions (Bennett, 2012). Furthermore, aside from the harm to children's wellbeing of their parents' income being halved as punishment for the child's non-participation in an (early childhood care and education (ECCE) setting, there is also potential harm for children who as a result of this policy participate in poor quality monocultural services being run primarily as businesses for the ultimate profit of shareholders (Mitchell, 2014; Ritchie, Harvey, Kayes \& Smith, 2014).

\section{Swimming, Floating, Circulating in a Discursive/Policy Soup}

In recent years in Aotearoa, educators and education researchers have found themselves somewhat 'at sea' in the confusing discursive/policy 'soup' (Braun, Ball \& Maguire, 2011). This milieu is generated by the now thirdterm centre right government which in its education policy draws upon both neo-conservative and neo-liberal strands, with these policies currently fronted by a Māori Minister of Education, Hekia Parata. Contradictory discourses drawing on normative science approaches (see for example, Hattie, 2009) are juxtaposed alongside, but subtly overtaking the climate fostered by the previous, Labour led government advocating culturally responsive pedagogies that honoured Te Tiriti o Waitangi, acknowledging the importance of including te ao Māori (Māori worldviews) within education programmes. The government's selective use of faulty 'normal science' data has been critiqued by leading academics. Here is just one such example of such critique:

Bias is not normally controlled in meta-analyses. Thus a meta-analysis (however well designed) of poorly designed studies will inevitably lead to unreliable conclusions. It is a serious matter when government agencies use such conclusions to justify educational policy. (Snook, O’Neill, Clark, O’Neill \& Openshaw, 2009, p. 96) 
The government's policy announcement in 2012 that it intended to increase class sizes, was grounded in Hattie's (2009) work. It promptly aroused a barrage of criticism from teachers, principals and education academics (see for example, O’Neill, 2012). Minister of Education, Hekia Parata initially chose to ignore these calls for her to retract the policy, but eventually did so when it became clear that it was very unpopular with the voting public (Watkins, Kirk, Small \& Levy, 2012).

Meanwhile, since 2010 the primary school sector has had to cope with the imposition, with minimal consultation with teachers or principals, of compulsory 'national standards' in numeracy and literacy, a neo-conservative authoritarian policy that is generating a surfeit of allegedly comparable data, along with negative impacts of the intensification of staff workloads, curriculum narrowing and the reinforcement of a two tier curriculum, the positioning and labelling of children and unproductive new tensions amongst school staff' (Thrupp, 2014, p. 16). Of even more concern is the potential harm of the negative labelling of a young child as "below the national standard', in terms of their image of themselves and a learner, and of their families' views of their child's capabilities. Government early childhood education discourse has seen a shift from the holistic, symbiotic understanding of care and education as intrinsic to pedagogy, to a focus on increased participation in 'early learning'. The new Ministry of Education website suffers from historic amnesia, and it has become very difficult to obtain information such as reports from early childhood care and education advisory committees that used to be previously available.

Repeatedly rejecting criticisms from schools and education academics of the impacts of such policies, the government in 2014 introduced a New Zealand model of charter schools, which although publicly funded at a much higher rate than state schools, are not required to be run or staffed by qualified educators, or to follow the New Zealand curriculum, nor are they accountable to the public via the usual channels of the Education Ombudsman and the Official Information Act. This means it is difficult to obtain any information about how children and families involved in these schools are faring.

Meanwhile, a wide range of New Zealand researchers from many disciplines, particularly health and education, continue to highlight the need for government policy to address the poverty that constrains so many children and families, and severely impacts on the learning and achievement that the government policy espouses (Bishop, 2010; Boston, 2014; Boston \& Chapple, 2014; Hēnare, 2014; Henare, Puckey, Nicholson, Dale \& Vaithianathan, 
2011; Rashbrooke, 2014b; Snook \& O'Neill, 2014; Turner \& Asher, 2014). It seems that 'normal science' is used selectively to justify government policy, and that government increasingly chooses to ignore even its own ministries' research informed advice when this does not have an ideological fit with their intended policy direction.

\section{Pedagogical and Methodological Resistance in Education in Aotearoa}

As mentioned above Thomas Kuhn identified the 'symptoms of a transition from normal to extraordinary research' as involving the proliferation of alternative philosophical conceptualisations and explicit resistance to normal science (1970, p. 91). In this section, I provide some examples of such resistance from educational research in Aotearoa New Zealand. The first is the re-normalisation of Māori culturally preferred pedagogies in the work of Russell Bishop and Mere Berryman (Bishop \& Berryman, 2006; 2009). This resistance can be viewed as a response to the negative impacts of white settler colonisationon Māori families and communities, whereby education has served as a key tool of assimilation. Next I discuss the revalidation of culturally sanctioned beliefs and values, including in particular spiritual domains, in the early childhood assessment models developed by Lesley Rameka (2012a; 2012b; 2015) and Pauline Luafutu-Simpson (2011). The last example is the collective, collaborative process demonstrated by Māori researchers and educators in generating a kaupapa Māori model to sit alongside the 'national standards' for literacy and numeracy in mainstream schools (Hohepa \& Rau, 2012). In offering responses that seek to re-normalise te ao Māori, as well as Samoan pedagogical understandings, these initiatives also provide inspiration for the transformation of educational programmes to be responsive and inclusive of the 'diversity of diversities' posited in situations of superdiversity.

In the work of Professor Russell Bishop, Dr Mere Berryman and colleagues involved in the Te Kotahitanga project, an explicit attempt was made to renormalise Māori conceptualisations, integrating these within the pedagogies of secondary school teachers. After interviewing Māori secondary students (and their families) as to what kinds of pedagogical approaches worked best for them, the researchers identified what they term 'the Kotahitanga effective teacher profile', which incorporates:

- manaakitanga: caring for students as Māori and acknowledging their mana [pride, esteem, integrity] 
- mana motuhake (legitimation, authority, integrity, identity): having high expectations

- ngā whakapiringatanga: careful organisation of the specific individual roles and responsibilities required in order to achieve individual and group outcomes

- wānanga and ako: using a range of dynamic, interactive teaching styles

- kotahitanga (collaboration towards a common vision): teachers and students reflecting together on student achievement in order to move forward collaboratively (Bishop \& Berryman, 2009, p. 27-32).

Key to the successful implementation of this approach is that teachers have both pre-service and in-service opportunities to reflect critically on the discursive contexts in which they are working, and in particular, to identify and critique discourses that promote deficit notions that pathologise the lived experiences of Māori students' (Bishop, 2010, p. 132). Instead of allowing these deficit discourses to distance themselves from connection with Māori students and from responsibility for their learning, the Kotahitanga model supports teachers to generate a sense of respectful, relational engagement with their students (Bishop, Ladwig \& Berryman, 2014).

In her work to identify a Māori model for assessment in early childhood settings, Lesley Rameka (2012a) drew on kaupapa Māori, a theoretical and transformative philosophy grounded in Māori onto-epistemologies (Mahuika, 2008; Pihama, Smith, Taki \& Lee, 2004; Smith, 1997). Rameka describes kaupapa Māori as "a movement of resistance and revitalisation" (2015, p. 37). Her study aimed to be transformative for Māori children and families, 'by challenging, critiquing and transforming dominant educational perceptions such as views of the Maori child, the nature of learning, pedagogy and culturally valued learning' (2012a, p. 9). In deepening their engagement with kaupapa Māori aspects such as wairuatanga (spiritual interconnectedness) in their assessment of children, the participating kaiako (teachers) felt a sense of empowerment:

For the case study kaiako, recognition of the diverse nature of Maori ways of knowing and being provided a sense of freedom and comfort not only to be Maori, but to be Maori differently. They recognised that there are many ways to be Maori and this supported the development of their own processes and protocols, for their whānau [families], community and context (Rameka, 2012a, p. 15). 
This experience suggests that re-engagement of spiritual interconnectedness and spiritual wellbeing is a form of resistance against 'normal science', the paradigm of which has disavowed recognition of spiritual dimensions, privileging positivism and cognition over embodied, intuitive and spiritual ways of knowing. Rameka's work repositions these Māori ways of being and knowing, affirming the 'spiritual nature' both of Māori children and of the worlds in which they are learning (Rameka, 2012a, p. 18).

In another project, which like the work of Rameka arose from critique of the 'mainstream' model of assessment for early childhood settings when applied to those whose culture, language and values differed from that of the dominant group, Pauline Luafutu-Simpson (2011) has identified a Samoan model for assessing the learning of young children. She highlights the tendency for Pākehā (of European ancestry) to dismiss resistance to the favoured model of assessment (narrative 'learning stories') by positioning the difficulties experienced by teachers in 'diverse' centres as 'novices', 'without acknowledging that the framework itself may need to be evaluated' (Luafutu-Simpson, 2011, p. 16). Spirituality again features strongly in this Samoan framework, since Fa'a Samoa (Samoan worldview) 'is a collection of spiritual and cultural values that motivates people ... It is the heritage of people' (Tui Atua, as cited in Luafutu-Simpson, 2011, p. 57). Another discourse reinstated in this model is that of alofa (aroha in Māori), re-affirming/re-claiming the central importance of love and care as central tenets of early childhood care and education.

The Māori researchers and educators who held the responsibility for developing a set of indicators of achievement for learners in Māori medium schools (schools which teach through the medium of Māori language) to parallel the 'national standards' in literacy and numeracy for 'mainstream' schools, were cognisant of their positioning within a milieu of contradictory discourses and in particular of the tensions in relation to the imposition of this assessment model within a Māori philosophical frame:

Whanaketanga developers had to address a fundamental issue-critical differences between the notion of standards coupled with the expectation that all students should be at a certain „place“ at a certain time, and the philosophical positions they and many others working in Maori medium settings hold about how students learn and about how achievement should be expressed. (Hohepa \& Rau, 2012, p. 69) 
They therefore collaborated in determining a set of principles to guide their process, and which aligned with their philosophical positioning. These included:

- sensitivity and responsiveness to linguistic issues such as dialectical differences and bilingual code-switching;

- fulfilment of Maori aspirations for language regeneration and cultural transmission;

- validation of Maori knowledge. (Hohepa \& Rau, 2012, p. 69)

Another stance that clarified their perspective was the deliberate choice of terminology, choosing the term 'whanaketanga (literally 'growth' or 'development'), rather than the Maori term for standards (paerewa)... in order to denote and focus on growth and progression of the child, rather than privileging the notion of a standard that children must reach' (Hohepa \& Rau, 2012, p. 69). These stances were enactment of tino rangatiratanga, collective determination of aspirations for the benefit of the wider community.

\section{Some Considerations}

Western cognivist approaches to learning and assessment fail to acknowledge the foundational significance of children and families' spiritual, social, cultural and emotional wellbeing. In ignoring the validity of other ways of being knowing, doing and relating, and instead focussing on increasingly prescriptive, 'normative' standards for learning, these approaches are inadvertently excluding an increasingly large sector of the population, those who do not fit within these 'normal' parameters. In the same way that 'normal science' has shifted capacities for healing has shifted from the arena of holistic and in particular spiritual wellbeing, to the realm of medical science with its compartmentalised pathological orientation (Cram, 2002), education is in danger of pathologising those who do not fit within the dominant paradigm.

For Māori and other ethnic groups within Aotearoa, such as Pacific Islands' peoples, in engaging within both scientific and educational research methodologies, there is an aspiration for self-determination, and for continuity of their cultural philosophies which include the goal of spiritual, cultural, and economic wellbeing for the greater collective. For those of us who represent the dominant cultural grouping, it is important that we recognise, foster and support the transformative potential of these Indig- 
enous and other non-western models, recognising that the benefits of this transformation will be likely to serve all members of the community, rather than perpetuating the benefits of a privileged few. This is the educational challenge that is increasingly faced as countries like Aotearoa (New Zealand) begin to recognise and address the issues created by superdiversity.

\section{References}

Bennett, P. (2012). Social obligations mean better outcomes for children. Wellington: New Zealand Parliament. Retrieved from http://beehive.govt.nz/release/social-obligations-mean-better-outcomes-children.

Bishop, R. (2010). Diversity and educational disparities: The role of teacher education. In Educating teachers for diversity: Meeting the challenge (pp. 119-135). Paris: OECD Publishing.

Bishop, R., \& Berryman, M. (2006). Culture speaks. Cultural relationships and classroom learning. Wellington: Huia.

Bishop, R., \& Berryman, M. (2009). The Te Kotahitanga effective teaching profile. Set. Research information for teachers, 2, 27-33.

Bishop, R., Ladwig, J., \& Berryman, M. (2014). The centrality of relationships for pedagogy: The whanaungatanga thesis. American Educational Research Journal, 51(1), 184-214.

Boston, J. (2014). Child poverty in New Zealand: Why it matters and how it can be reduced. Educational Philosophy and Theory, 46(9), 962-988.

Boston, J., \& Chapple, S. (2014). Child poverty in New Zealand. Wellington: Bridget Williams Books.

Braun, A., Stephen J. Ball, S. J., \& Maguire, M. (2011). Policy enactments in schools introduction: Towards a toolbox for theory and research. Discourse: Studies in the Cultural Politics of Education, 32(4), 581-583.

Cram, F. (2002). Maori and science: Three case studies. Final report. Auckland: Auckland Uniservices.

Education Counts. (2014). Participation in early childhood education. Ministry of Education.

Education Review Office. (2010). Success for Māori children in early childhood services. Wellington: Education Review Office.

Education Review Office. (2012). Partnership with whānau Māori in early childhood services. Wellington: Education Review Office.

Education Review Office. (2013). Working with Te Whāriki. Wellington: Education Review Office.

Hattie, J. (2009). Visible learning. A synthesis of over 800 meta-analyses relating to achievement. Abingdon, Oxon: Routledge.

Hēnare, M. (2014). Pōhara, tōnui, kōkiri: Imagine a child and whānau-centred economy of equality, wealth creation and poverty removal. In V. M. Carpenter, \& S. Osborne (Eds.), Twelve thousand hours. Education and poverty in Aotearoa New Zealand (pp. 44-66). Auckland: Dunmore. 
Henare, M., Puckey, A., Nicholson, A., Dale, C. M., \& Vaithianathan, R. (2011). He ara hou: The pathway forward. Getting it right for Aotearoa New Zealand's Māori and Pasifika children. Wellington: Every Child Counts.

Hohepa, M. K., \& Rau, C. R. (2012). Ngā Whanaketanga: Minimising contradictions and maximising opportunities for teacher learning. Waikato Journal of Education. Te Hautaka Matauranga o Waikato, 17(2), 62-78.

Kuhn, T. S. (1970). The structure of scientific revolutions (2nd ed.). Chicago: University of Chicago Press.

Luafutu-Simpson, P. (2011). Exploring the teaching of effective approaches for assessing young Samoan children's learning in early childhood centres: Developing an authentic Samoan lens. Wellington: Ako Aotearoa. National Centre for for Tertiary Teaching Excellence.

Mahuika, R. (2008). Kaupapa Māori theory is critical and anti-colonial. MAI Review, 3, 1-16.

Mara, D. (2014). Pacific students: Positioned as failures, targets and consumers. In V. M. Carpenter, \& S. Osborne (Eds.), Twelve thousand hours. Poverty in Aotearoa New Zealand (pp. 102-122). Auckland: Dunmore.

Marriott, L., \& Sim, D. (2014). Indicators of inequality for Māori and Pacific people. Wellington: Victoria University Business School.

Mitchell, L. (2014). Linda Mitchell: Put children's education before shareholders. Auckland: New Zealand Herald.

New Zealand Ministry of Education. (1996). Te Whāriki. He whāriki mātauranga mō ngā mokopuna o Aotearoa: Early childhood curriculum. Wellington: Learning Media. New Zealand Ministry of Education. (2007). The New Zealand Curriculum for Englishmedium teaching and learning in years 1-13. Wellington: Learning Media.

O'Neill, J. (2012). Class size matters to those who struggle most. Palmerston North: Massey University.

Pihama, L., Smith, K., Taki, M., \& Lee, J. (2004). A literature review on kaupapa Maori and Maori education pedagogy. Auckland: The International Research Institute for Maori and Indigenous Education.

Rameka, L. (2012a). Culturally located assessment in early childhood education. Waikato Journal of Education. Te Hautaka Matauranga o Waikato, 17(2), 7-21.

Rameka, L. (2012b). Whakapapa: Culturally valid assessment in early childhood. Early Childhood Folio, 16(2), 33-37.

Rameka, L. (2015). Whatu: A Māori approach to research. Waikato Journal of Education, 20(2), 39-46.

Rashbrooke, M. (2014a). How New Zealand's rich-poor divide killed its egalitarian paradise. London: Guardian News and Media Ltd.

Rashbrooke, M. (2014b). Poverty in New Zealand: Even worse than we thought. Inequality. A New Zealand Conversation. Sparking debate about income gaps, the damage they do, and how to narrow them.

Ritchie, J., Harvey, N., Kayes, M., \& Smith, C. (2014). Our children, our choice: Priorities for policy. Child Poverty Action Group Policy Paper Series. Part Two: Early Childhood Care \& Education (ECCE). Auckland: Child Poverty Action Group.

Royal Society of New Zealand. (2013). Languages in Aotearoa New Zealand. Wellington: Royal Society of New Zealand. 
Smith, G. H. (1997). The development of Kaupapa Maori: Theory and praxis. (Doctor of Philosophy in Education Thesis), Auckland: University of Auckland.

Snook, I., \& O'Neill, J. (2014). Poverty and inequality of educational achievement. In V. M. Carpenter, \& S. Osborne (Eds.), Twelve thousand hours. Educational poverty in Aotearoa New Zealand (pp. 19-43). Auckland: Dunmore.

Snook, I., O’Neill, J., Clark, J., O’Neill, A.-M., \& Openshaw, R. (2009). Invisible learnings? A commentary on John Hattie's book: Visible learning: A synthesis of over 800 meta-analyses relating to achievement. New Zealand Journal of Educational Studies, 44(1), 93-106.

Spoonley, P. (2015). New diversity, old anxieties in New Zealand: The complex identity politics and engagement of a settler society. Ethnic and Racial Studies, 38(4), 650-661.

Statistics New Zealand. Tatauranga Aotearoa. (2013). Half a million Aucklanders born overseas. Wellington, New Zealand: Statistics New Zealand.

Thrupp, M. (2014). At the eye of the storm: Researching schools and their communities enacting National Standards. New Zealand Journal of Educational Studies, 49(1), 6-20.

Thrupp, M., \& Easter, A. (2013). 'Tell me about your school': Researching local responses to New Zealand's National Standards policy. Assessment Matters, 5, 94-115. Turner, N., \& Asher, I. (2014). Child poverty and health (pp. 13-37). Auckland, NZ: Child Poverty Action Group.

Vertovec, S. (2007). Super-diversity and its implications. Ethnic and Racial Studies, 30(6), 1024-1054.

Watkins, T., Kirk, S., Small, V., \& Levy, D. (2012). Backlash forces government class size u-turn. Wellington: Stuff, NZ.

\section{Author:}

Jenny Ritchie, Associate Professor

Victoria University of Wellington

Faculty of Education

Aotearoa

New Zealand

Email: Jenny.Ritchie@vuw.ac.nz 